\title{
One Paradoxical Nature of Market Economy
}

\section{Rongqing Dai ${ }^{*}$}

Freelance Philosopher, New Jersey, USA

*Corresponding author: Rongqing Dai, PHD, Freelance Philosopher, New Jersey, USA, Tel: +0017323953163, E-mail: ronald_dai@yahoo.com

Rec date: May 04, 2016; Acc date: May 21, 2016; Pub date: May 26, 2016

Copyright: (C) 2016 Dai R. This is an open-access article distributed under the terms of the Creative Commons Attribution License, which permits unrestricted use, distribution, and reproduction in any medium, provided the original author and source are credited

\begin{abstract}
The goal of individual enterprise to maximize the profit for shareholders is often in conflict with the economic goal of a society to improve the standard of living of its citizens in general. This conflict might be less compromisable than it is usually assumed to be due to some intrinsic logical uneasiness within any economic system, which would perpetually create uncertainties in the market. As a matter of fact, market economy is paradoxical in nature in the sense that some good will of development in a market economy would logically hurt the economy itself. This paradox is the result of logical conflict of the following two facts: 1) economic development would aim at increasing productivity which would potentially lead to a reduction of human workforce in individual enterprises. This is because of the common goal of maximizing profit through cost reduction, including the reduction of the cost of human resource; 2 ) the ultimate economic responsibility of a society to increase the standard of living for ordinary citizens would require a higher employment rate with increasing wage rate since the major income for most families is employment wages.
\end{abstract}

This writing provides an in depth philosophical analysis on the logical conflict that determines this paradoxical nature of market economy that causes incessant uncertainties in the market, from which we might see some important tasks for us to carry out in the future.

Keywords: Economic growth; Standard of living; Cost reduction; Science and technology; Automation; Market economy

\section{Introduction}

It has been acknowledged for quite a long time that the economic responsibility at an enterprise level is often not in line with economic responsibility at a societal level. For the former the main responsibility is to maximize the profit for shareholders, while for the latter the chief responsibility is to increase the standard of living of ordinary citizens in a society.

One direct consequence of the difference between the economic goals at individual and societal levels is to cause constant uncertainties in the market. As we know that one of the fundamental concerns of economic studies is to help the society to be better prepared for potential economic uncertainties, no matter through simple demand and supply analyses, advanced mathematical modeling, statistical investigation, or various types of numerical simulations. Many factors have been viewed as important causes for different levels of economic uncertainties such as unforeseeable or uncontrollable natural disasters, political turmoil, war, as well as individual situations created by normal competitions or irrational fights between rivals during market competitions, and so on. Even though sometimes an adverse condition for some economic entities is caused by activities of other entities for their own sake, none of these conditions would be universally considered favorable. However, there is one intrinsic cause of perpetual economic uncertainties for the whole market which is not only universally favored but even treated as utmost economic responsibility of all economic entities in market economy: pursuing the goal of maximizing the profit for shareholders through reducing cost of human resources. This is obviously in conflict with the ultimate goal of social economic growth: to increase the standard of living of ordinary citizens in a society, which also is supposed to be the ultimate goal of scholars in economics including people who participate in simulating economic systems by numerical computations.

The goal of increasing public living standard in general would no doubt require increasing per capita cost for employers who hire people for their businesses since for most families around the world the main source of income for living is their employment wages. But on the other hand, it is not hard for us to see that the fundamental goal of reducing cost of every single business owner would create the temptation of reducing the size of employees, unless the increase of the size of business would create the need of maintaining or even increasing the size of employees. While this temptation of lowering business cost through reducing the size of employees is very clear and certain, the need of increasing the size of employees (which is in line with the ultimate goal of economic growth of a society) is highly contingent. Even if the size of business increases the need of increasing the size of employees is not guaranteed, but the temptation of reducing cost would always exist. That is the catch. It is apparently a simple math that one can always save extra human resource cost by increasing the work load of existing employees, which has indeed been a very common practice around the world whenever it is considered as viable. Consequently, any economic system would automatically generate incessant economic uncertainties as a result of the conflict between the common goal of collective growth of economic welfare and the universal goal of cost reduction by stake holders in the system.

Furthermore, market economies are not static systems. The long term well-being of any market economy would depend on the development in many aspects within the market. However, one important goal of economic development is to help business owners in private sectors to increase work efficiency per capita, which indicates a reduced need for human employees for a given production size. 
Therefore, the employment rate in a market would not only be upset by human desire of saving cost when sales going down, but also would be hurt by the economic development at good will itself.

Now we see the two sides of a logical conflict within any economic system that would create an intrinsic source of perpetual economic uncertainties in terms of social economic growth:

Economic development would aim at increasing production efficiency which would potentially lead to a reduction of the sizes of human workforce in individual enterprise. This is because that one common goal of individual enterprises is to maximize profit through cost reduction, including the reduction of human resource cost; the ultimate economic responsibility of a society is to increase the standard of living for the ordinary citizens, which would require a higher employment rate with increasing wage rate since the major income for most families is employment wages.

This is a paradox in the sense that the good will of economic development would logically hurt the economy itself. Therefore, while scholars $[1,2]$ have been mainly concerned with the awareness of social responsibility and pro-social behavior of individual economic entities as the way to curtail the negative effect of the disagreement of economic responsibility at individual and societal levels, we can see that the issue of the conflict between economic responsibility at those two levels is not just a simple issue of the willingness of paying dues for philanthropy or ecological protection by business owners, but rather a profound philosophical issue of intrinsic logical uneasiness. The above mentioned intrinsic source of economic uncertainties from within any economic development itself manifests an economic relativity [3] in the sense that the meaning of a good economy is relative to each different individual within the economic system. The impact of this economic relativity on economic development should not be underestimated, which is worth special attention by professionals who intend to make economic predictions through analytic or numerical studies.

\section{Mutual Influence between Economic Development and the Development of Science and Technology}

The development of science and technology has been a major driving force to the economic development in modern societies. One positive aspect of the scientific and technological impact upon social economy is that it would potentially create the need of human workforce to conduct new scientific researches, to develop, produce, transport and store, and then sell new industrial products, to provide various services, and to manage all relevant activities. This would no doubt help the economy of a society by boosting employment in general. One important reason for the needs of increasing human workforce would be the emergent needs of new products and services as the results of new scientific and technological breakthroughs, which would offer convenience in everyday life or improve the quality of human life or enhance human capacity to deal with natural or social challenges. Examples include internet services, personal tablets, smart phones and scientific way of growing crops or scientific way of healing and many more.

However, one type of scientifically created industrial means, in the form of hardware or software, plays a very special role in economic processes, which is the type of means that helps either to increase productivity or facilitate and advance management tasks in workplaces [4-6]. The industrial applications of automation and information technology could provide typical examples of this type. Even though the production and application of products of this type would also create needs of human workforce, they are often designed with clear motives of replacing human operations with the work of machines and computers. As a matter of fact, because of the logical possibility of replacing human operations by machines as a result of the development of robotic technology and some forms of information technology, the purpose of using machines in workplace becomes very different from what people might have in mind a couple of centuries ago [5].

On the other hand, the local, regional, and global economic development would boost scientific and technological development, including original discoveries and inventions. This is not only because economic activities would bring up new practical needs that would demand and stimulate scientific and technological innovations, but also because economic development would help scientific and technological activities in the following two important ways: 1) economic development would accumulate sufficient wealth to support advanced and systematic scientific and technological researches and innovations; 2) industrialized production and commercialized circulation would provide the material and human resources that are of critical importance for scientific and technological development.

Therefore, the economic development and the development of science and technology would together form a mutually dependent dynamic system (which we might call as economic-scientifictechnological system). Within this system the development of science and technology has two economically conflicting mandates: 1) to improve life quality and working ability of a society, and 2) to reduce the use of human beings in the existing working units (and thus reduce employment) in the society. Obviously, if economic development could never create new jobs to compensate the reduction of jobs due to the development of science and technology, then the development of science and technology would keep ruining the economy by continuously removing jobs from the system and thus potentially reduce the societal buying power which would in turn hurt the business owners in the system.

Even if the system could adjust itself to create new jobs to compensate the job shortage resulting from the reduction of jobs by the development of science and technology, there would be a lag between the time when old jobs were lost and the time when new jobs are created. The main reason is because while the removal of jobs after the adoption of new technology might be inevitably driven by legitimate financial concerns, the creation of new jobs could be quite contingent at any given moment. Therefore, the equilibrium between the creation and reduction of jobs due to economic development and the development of science and technology would be very dynamic with periods of low job needs during which the needs of human resources are relatively low. The periods of low job needs would automatically occur in individual businesses when the needs of human resources are reduced through the adoption of some new technology. If the occurrences of the low job needs are random across the economic system, then it might have minor impact upon the overall economy since when some businesses are reducing the size of human resources some other businesses might be increasing the size of human resources. However, if some common wave of technological development causes a wide-spread low job needs at the same period of time then the system might experience some more serious economic shock upon its job market (and thus the public buying power) due to the scientific and technological development. 
This tells that in addition to some other factors that might cause periodical economic slowdown or even crises, the automatic selfevolution of the system of economic development and scientific and technological development might also contribute to periodical economic difficulties. That might raise some concerns about what we can do about it or, more seriously, whether we can always pull ourselves out of the period of low job needs caused by the development of science and technology and then reach the dynamic equilibrium.

\section{A Special Competition}

Because of the potential removal of jobs from market by the development of the fundamental driving force of modern economyscience and technology, one perpetual challenge to economists and market influencers such as politicians, social activists, as well as enterprises would be how to balance the loss of jobs resulting from the development of science and technology with the creation of jobs through the creation of social needs. Or more profoundly speaking, the challenge is how to balance between the material aspect of the evolution of civilization, represented by science and technology, and the humanity aspect of the evolution of civilization, symbolized by the general living quality of the public around the world.

There have been two types of idealistic thinking about how to balance these two aspects of human civilization, one is positive and one is negative. The negative one is to stop or manually delay the development of science and technology in order to maintain high level of demand of human workforce in the market; and the positive one is to make some artificial arrangement so that we might maintain high demand of human workforce while enjoy the advantage of technology. The following paragraph by Shaiken, the author of "The Human Impact of Automation" [4] is a typical example along this idealistic line:

The real choice is developing computer technology such that within the workplace, the technology utilizes the extraordinary talents human beings can contribute. And, outside of the workplace, utilizing technology in a way that shares the gains in productivity so that unemployment is not the consequence of technological change. In both areas, there has been remarkably little exploration of the unstated assumptions underlying the utilization of technology or the alternatives. To use computer technology in a human way-to realize its extraordinary potential to enrich jobs and provide increased productivity for the society-requires a careful, thorough exploration of the alternatives, and the placing of human beings at the central point of the equation rather than as an afterthought.

However, both of these types of idealistic thinking would not work, at least not work for capitalist free market economy. This is because they are against social laws of human civilization, especially social laws in capitalist society. In fact, no matter capitalists, socialists, communists, or most other-ists have so far viewed science and technology as most important force driving the evolution of civilization. Therefore, any effort of systematically hindering or delaying the general development of science and technology for the sake of employment would not attract much support around the world and thus would not succeed. Similarly, any artificial restriction of application of newly developed technology in workplaces solely for the purpose of balancing the usefulness of technology and the employment needs would not work, at least would not work in capitalist economy since it is against the principle of free market. At least for capitalist market economy, creating jobs to compensate the loss of job due to the development of science and technology becomes a separate task that would not concern the people who work for the development of science and technology.

Now we can see a competition between two relatively independent (but still mutually coupled to certain extent) tasks: scientific and technological development and job creation. This is a very special competition because it is basically driven by the development of science and technology and thus it is more like a relay than a competition. But it is a competition in the sense that the development of science and technology would not pause to wait for the creation of jobs to catch up.

We are now facing such two questions: 1) Are there any general patterns for the creation of new jobs when large amount of jobs are lost due to the development of science and technology? 2) Can we always pull ourselves out of the period of low job needs by creating new jobs to compensate the loss of jobs in time?

For the past few centuries, human beings have experienced many times of mass replacement of human operators by machines due to new technological revolutions. But each time the job market recovered shortly after new jobs were created because of the emergence of new social needs with greater market demand of products or services and thus it just appeared to be a transition from one social living style to another except for the disruptions by a few regional or global wars. A very common pattern during those transitions is that some new industrial products (software or hardware) were created which brought up new demand of human workforce in the new line of design, production, storage/supply, and sales/services. Within this pattern there are two basic factors: 1) new products or services are of values to the society therefore there would be market demand of them; 2) the production of the products and the provision of services need human workforce.

Obviously, the second factor mentioned in the above paragraph, i.e. the emergence of new needs of human workforce due to the emergence of new market demand of products and services, is critical for the recovery of job market. However, there is no systematic rationalized theory of how the market would absorb extra workforce created by newly developed technology in general even though practically it seems that the market has always been capable of doing it after certain period of turmoil. Besides, the main difference between the upcoming new wave of the industrial revolution and any of the previous ones is that it aims at a radical (if not complete) replacement of human workforce by robots or general computer systems. This would make it a really meaningful question whether we can still pull ourselves out of the period of low job needs once the revolution of mass automation comes in the near future.

If one day, as a result of highly advanced and extensive automation, all production and service jobs would be done by robots, and human beings would just enjoy life (or maybe enjoy fighting or killing each other), then the answer to the question of last paragraph would be simple: we would not pull ourselves out of the period of low job needs. This would obviously create a trouble to market economy. This is because that based upon the rule of game of free market economy people earn their rights to consume through transactions. When a person gets food through a transaction, he pays money to the party that offers food; and then he needs to offer something he owns through some transaction to replenish his own supply of money. For most people the main thing they could offer for money is their own labor for white or blue collar jobs. Once the demand for human labor for white 
or blue collar jobs are eliminated by robots and general computer systems, then most people might lose their capability to purchase and thus to lose their right to consume, which would in turn to reduce the general buying power in the market.

There might still be an extreme scenario which would validate the free market economy game even when no human labor for white or blue collar jobs is needed. In this scenario most people own some robot-operated companies that would provide goods and services to make money for them. But the chance for human civilization to directly enter such scenario after the automation revolution comes is not very high. The bright side of the issue is, however, even if that hypothetical scenario of an economy with complete robotic service and production is valid, technically it could be realized only through a gradual transition period.

As a matter of fact, no matter if the day when all the production or service jobs being replaced by robots would come or not, the gradual advancement of replacing human man power in various work places seems not stoppable. Therefore, it seems that we do need to prepare ourselves in two areas for the potential challenge from automation revolution: 1) we might need some in depth study on how to make market systematically absorb extra workforce whenever new automation technology starts to replace man power; 2) we might need some sophisticated philosophical thinking to solve the potential problems of social distribution of wealth before we could be ready to embrace the coming of new wave of automation revolution. What really matters behind the scene is a special power: the power of fairness which might sound very familiar to people around the world but actually still remains strange to most people of this world with its very nature $[7,8]$ hidden behind the veil.

So far in human history the capitalist system has been the most efficient economic system since some other trial systems have failed in the history. But it might become a question whether a simple capitalist system, without a thorough knowledge about the power of fairness, would continue to be efficient when the new industrial revolution through automation would come. If yes, then we might need to understand why it is yes before we accept the answer; if no, then we need to think about how we could help to improve.

\section{Closing Words}

The conflict of economic responsibility at different social levels might be less compromisable than we might have thought in the past. This is not solely because the unwillingness of paying social dues by individual enterprises as we used to assume, but because some deep rooted intrinsic logic within any economic system, which warrants more in depth philosophical thinking about the dynamics of economy. As we might see, from the discussion of this writing, that the development of science and technology is not only a miracle producer for economy in a very positive sense but also a most unpredictable intrinsic source of economic uncertainties, especially for free will and transaction based market economy. One of the biggest challenges economists and the ordinary public might need to prepare to embrace in the near future would be the coming era of highly automated industrial production by robots and much more efficient computerized services and management operations, without the need of the presence of Homo sapiens in many traditionally human occupied places. This would no doubt have a fundamental impact upon the existing economic theories, as well as the philosophy about our civilization.

As Shaiken noticed [4], "engineers, particularly in academia, who deal with control or automation issues relating to the workplace, have remarkably little contact with those directly affected by design decisions-that is, workers and first-line supervisors in production." This social phenomenon is indeed very natural and would be staying the same in the future since it really should not be a concern of those engineers to preserve jobs of others in workplace. Rather, "automation does not assist, but replaces human operators" as pointed out by Srivastava the author of "Automation-It's Impact on our Lives" [6]. However, the issue of the replacement of human operators by automation has to be one of the major concerns of economists and market influencers around the world or more precisely it should be an undeniable responsibility of economists, philosophers, and market influencers around the world to understand the nature of the issue and search for solutions to deal with the issue. The brief discussion presented in this writing is intended to contribute to such understandings and searches.

\section{References}

1. Clark JM (1916) The Changing Basis of Economic Responsibility. Journal of Political Economy 24: 209-229.

2. Benabou R, Tirole J (2010) Individual and Corporate Social Responsibility. Economica 77: 1-19.

3. Dai R (2014) Chaotic Order: A Consequence of Economic Relativity. Complexity in Economics: Cutting Edge Research. Marisa Faggini and Anna Parziale Springer 117-135.

4. Shaiken H (1986) The Human Impact of Automation. IEEE Control Systems Magazine.

5. Andrew URE (1835) The philosophy of manufactures; or, an exposition of the scientific, moral, and commercial economy of the factory system of Great Britain. New York, A.M. Kelley

6. Srivastava AK. Automation-Its Impact on our Lives.

7. Dai R (2016) A Short Introduction to the Paradoxical and Dynamic Nature of Fairness. J Civil Legal Sci 5: 168.

8. Dai R (2015) A brief discussion on fairness analysis. Outskirts Press. 